\title{
THE ANALYSIS OF INFLUENCE USE PRODUCTION FACTORS ON RAINFED LOWLAND RICE FARMING IN VILLAGE SERINDANG, DISTRICT OF TEBAS SAMBAS REGENCY
}

\author{
Listiasari ${ }^{1}$ ) Jajat Sudrajat and Adi Suyatno ${ }^{2}$ ) \\ 1) Mahasiswa Fakultas Pertanian Universitas Tanjungpura \\ 2) Dosen Fakultas Pertanian Universitas tanjungpura
}

\begin{abstract}
This study was aimed to determine the effect of the use of production factors rainfed lowland rice farming in Serindang, Tebas, Sambas regency. The method used in this study was a survey method. The location of research was purposively selected in the Serindang, Sambas by considering of farming was the central high produced of rice and it was the main income for the farmers.

The primary data was collected by simple random sampling while secondary data was collected from Central Bureau Statistic (BPS) and Village Chief Office. The numbers of respondents were 37 farmers from 730 populations of rainfed rice farmers. The variables examined in this study covered a land area, number of seeds, Urea fertilizer, NPK fertilizer, the amount of herbicides, insecticides, and the non-family workers.

The analysis of production factors use in Serindang was Regression Test CobbDouglas function. The results of the analysis showed that the factors of production land area were significantly affect production, while the factors of production of seed, urea fertilizer, NPK fertilizer, herbicides, insecticides and non family workers were not significantly affect production. It was influenced by the use of local seed that was not responding toward fertilizing and erroneously rainfall affected uncontrolled irrigation that was influencing the rice growth.
\end{abstract}

Keywords: Factors of production, rice, rainfed lowland 


\section{PENDAHULUAN}

Padi (oryza sativa) adalah bahan baku pangan pokok yang vital bagi rakyat Indonesia.. Padi merupakan tanaman yang membutuhkan air cukup banyak untuk hidupnya. Biasanya padi ditanam di sawah yang menyediakan kebutuhan air cukup untuk pertumbuhannya.

Sawah tadah hujan adalah sawah yang sumber airnya tergantung atau berasal dari curah hujan tanpa ada irigasi atau tata air permanen. Sawah tadah hujan umumnya terdapat pada wilayah yang posisinya lebih tinggi dari sawah lainnya sehingga waktu tanam padi sangat tergantung pada datangnya musim hujan. Lahan sawah tadah hujan (STH) di Indonesia dengan luasan 2,1 juta ha dapat menjadi lumbung padi kedua nasional setelah lahan sawah irigasi (Badan Litbang Pertanian, 2008).

Kalimatan Barat merupakan salah satu propinsi di Indonesia yang sebagian penduduknya menyandarkan kebutuhan hidup dibidang pertanian, sehingga pertanian di daerah ini banyak ditekankan pada pertanian tanaman pangan sebagai prioritas utama. $\mathrm{Hal}$ ini dimaksudkan untuk meningkatkan produksi dan pendapatan usahatani padi agar tercapai kemakmuran dan kesejahteraan petani, melalui kebijakan dan langkah strategis yang telah ditentukan oleh pemerintah pusat dan daerah.

Kecamatan Tebas termasuk klasifikasi iklim tropis basah dengan suhu berkisar antara $20^{\circ} \mathrm{C}$ sampai $34^{\circ} \mathrm{C}$ dengan suhu rata-rata $30^{\circ} \mathrm{C}$ dan rata-rata curah hujan 3.011 $\mathrm{mm} /$ tahun atau $250 \mathrm{~mm} /$ bulan dengan jumlah hari hujan 164 hari/tahun atau rata-rata 14 hari hujan per bulan (BPP Kecamatan Tebas, 2011). Daerah Kecamatan Tebas termasuk klasifikasi iklim bulan basah (BB) dikarenakan curah hujan $>100 \mathrm{~mm} / \mathrm{bulan}$ (Anonim, 2011) sehingga sangat berpotensi dalam perkembangan usahatani padi lahan tadah hujan. Adapun data curah hujan Kecamatan Tebas yang dioleh dari Badan Penyuluhan Pertanian Kecamatan Tebas (2011) sebagai berikut:

Tabel 1. Data Curah Hujan 5 Tahun Terakhir (2005-2009)

\begin{tabular}{|c|c|c|c|c|c|c|c|c|c|c|c|c|c|}
\hline \multirow{2}{*}{ Tahun } & \multicolumn{12}{|c|}{ Bulan } & \multirow{2}{*}{$\begin{array}{l}\text { Jumlah } \\
\text { (Mm/Hh) }\end{array}$} \\
\hline & 1 & 2 & 3 & 4 & 5 & 6 & 7 & 8 & 9 & 10 & 11 & 12 & \\
\hline $2005 \mathrm{Ch}$ & 254 & 46 & 44 & 105 & 289 & 85 & 180 & 76 & 231 & 465 & 307 & 497 & 2579 \\
\hline $\mathrm{Hh}$ & 9 & 5 & 7 & 5 & 13 & 7 & 7 & 7 & 8 & 16 & 16 & 16 & 117 \\
\hline $2006 \mathrm{Ch}$ & 363 & 225 & 154 & 185 & 192 & 199 & 130 & 125 & 227 & 298 & 276 & 360 & 2734 \\
\hline $\mathrm{Hh}$ & 16 & 11 & 10 & 14 & 11 & 9 & 8 & 7 & 14 & 15 & 15 & 15 & 145 \\
\hline $2007 \mathrm{Ch}$ & 385 & 131 & 122 & 115 & 169 & 398 & 393 & 20 & 239 & 200 & 226 & 346 & 2744 \\
\hline $\mathrm{Hh}$ & 9 & 9 & 8 & 11 & 10 & 12 & 11 & 6 & 9 & 12 & 19 & 21 & 137 \\
\hline $2008 \mathrm{Ch}$ & 327 & 144 & 190 & 83 & 64 & 165 & 269 & 178 & 142 & 338 & 410 & 675 & 2985 \\
\hline $\mathrm{Hh}$ & 10 & 6 & 13 & 7 & 4 & 9 & 13 & 9 & 12 & 16 & 14 & 24 & 137 \\
\hline 2009 Ch & 576 & 380 & 156 & 138 & 82 & 147 & 70 & 101 & 62 & 187 & 660 & 314 & 2872 \\
\hline $\mathrm{Hh}$ & 13 & 8 & 8 & 9 & 6 & 5 & 5 & 6 & 4 & 11 & 21 & 15 & 110 \\
\hline
\end{tabular}

Sumber : BPP Tebas, 2011

Desa Serindang merupakan salah satu desa yang berada di Kecamatan Tebas. Menurut Badan Penyuluhan Pertanian Kecamatan Tebas (2010) produktivitas usahatani padi desa Serindang cukup tinggi yaitu $35 \mathrm{Kw} / \mathrm{Ha}$. Hal tersebut didukung oleh data dari Badan Penyuluhan Pertanian Kecamatan Tebas (2010) sebagai berikut: 
Tabel 2. Produktivitas Usahatani Padi Lahan Tadah Hujan di Kecamatan Tebas Tahun 2010

\begin{tabular}{clcc}
\hline No & \multicolumn{1}{c}{ Desa } & Produktivitas (Kw/Ha) & Jumlah Petani (Orang) \\
\hline 1 & Segedong & 35 & 449 \\
2 & Pusaka & 35 & 560 \\
3 & Mensere & 34 & 814 \\
4 & Mekar Sekuntum & 34 & 551 \\
5 & Sei Kelambu & 35 & 663 \\
6 & Serumpun Buluh & 34 & 520 \\
7 & Matang Labong & 34 & 810 \\
8 & Maktanggok & 32 & 497 \\
9 & Serindang & 35 & 730 \\
10 & Bukit Segoler & 34 & 568 \\
11 & Batu Makjage & 34 & 688 \\
12 & Pangkalan Kongsi & 33 & 901 \\
13 & Dungan Perapakan & 34 & 615 \\
14 & Tebas Sungai & 33 & 2023 \\
15 & Makrampai & 34 & 695 \\
16 & Bekut & 33 & 619 \\
17 & Seberkat & 32 & 428 \\
18 & Maribas & - & 177 \\
19 & Seret Ayon & - & 247 \\
20 & Segarau Parit & 33 & 892 \\
\hline
\end{tabular}

Sumber : BPP Tebas, 2011

Sawah tadah hujan mempunyai potensi tinggi sebagai salah satu sentra produksi padi untuk memenuhi kebutuhan beras nasional. Masalah cekaman abiotik seperti curah hujan yang tidak menentu dan kesuburan tanah yang rendah merupakan masalah serius yang harus diatasi agar produksi padi dapat ditingkatkan. Adapun faktor-faktor produksi padi yang dimaksud adalah luas lahan, jumlah benih, pupuk, pestisida dan tenaga kerja.

\section{METODE PENELITIAN}

Metode penelitian yang digunakan adalah metode survey. Metode survey, yaitu penelitian yang diadakan untuk memperoleh fakta-fakta dari gejala-gejala yang ada dan mencari keterangan-keterangan secara faktual, dari suatu kelompok atau pun suatu daerah (Nazir, 1988:65)

Metode yang digunakan dalam penetapan lokasi pada penelitian ini adalah sengaja (purposive) yaitu di Desa Serindang Kecamatan Tebas Kabupaten Sambas dikarenakan usahatani padi pada desa tersebut termasuk sentra produksi yang cukup tinggi di Kecamatan Tebas dan usahatani padi juga merupakan sumber pendapatan utama petani di Desa Serindang.

\section{Populasi}

Menurut Sugiyono (2003:55) populasi adalah "wilayah generalisasi yang terdiri atas; obyek/subyek yang mempunyai kuantitas dan karakteristik tertentu yang ditetapkan oleh peneliti untuk dipelajari dan kemudian ditarik kesimpulannya" sedangkan menurut Nawawi (1991:141) populasi adalah keseluruhan objek penelitian yang dapat terdiri dari manusia, benda-benda, hewan, tumbuh-tumbuhan, gejala-gejala, nilai test atau peristiwaperistiwa sebagai sumber data yang memiliki karakteristik tertentu didalam suatu 
penelitian. Populasi dalam penelitian ini adalah penduduk Desa Serindang Kecamatan Tebas Kabupaten Sambas yang bekerja sebagai petani padi lahan tadah hujan sebanyak 730 orang.

\section{Sampel}

Menurut Sugiyono (2003:56) sampel adalah "sebagian dari jumlah dan karakteristik yang dimiliki oleh populasi tersebut. Bila populasi besar, dan peneliti tidak mungkin mempelajari semua yang ada pada populasi, misalnya karena keterbatasan dana, tenaga dan waktu, maka peneliti dapat menggunakan sampel yang diambil dari populasi itu".

Menurut Suparmoko (1991:42) mengatakan bahwa populasi yang lebih dari 200, maka dalam hal ini cara yang terbaik adalah dengan mengambil persentase tertentu, yaitu $5 \%, 10 \%, 15 \%$ dari jumlah populasi, maka sampel yang diambil adalah 5\% dari jumlah populasi 730 orang sehingga besar sampel yang diambil dalam penelitian ini adalah berjumlah $\mathrm{N}=730 \times 5 \%=36,5$ dan dibulatkan menjadi 37 orang petani padi di Desa Serindang Kecamatan Tebas Kabupaten Sambas.

\section{Sumber dan Alat Pengumpulan Data}

Adapun jenis data yang digunakan dalam penelitian ini adalah data primer dan data sekunder:

1. Sumber data primer, yaitu sumber data yang diperoleh langsung dari responden. Teknis pengambilan data yaitu dengan wawancara langsung dengan mengajukan daftar pertanyaan (kuisioner) yang diberikan kepada para petani.

2. Sumber data sekunder, yaitu sumber data yang diperoleh dari literature maupun instansi yang berkaitan dengan penelitian yang dilakukan. Teknik pengumpulan data melalui Kantor Kecamatan, Petugas Pertanian Kecamatan Tebas, Dinas Pertanian Kabupaten Sambas dan literatur yang mendukung.

\section{Analisis Data}

Analisis yang digunakan adalah fungsi produksi Cobb-Douglas yang dilinierkan. Menurut Soekartawi (2003) untuk memudahkan pendugaan terhadap persamaan fungsi produksi diubah menjadi persamaan regresi berganda dengan transpormasi logaritma, yaitu sebagai berikut:

$\log Y=\log a+b_{1} \log X_{1}+b_{2} \log X_{2}+b_{3} \log X_{3}+b_{4} \log X_{4}+b_{5} \log X_{5}+b_{6} \log X_{6}+b_{7} \log X_{7}$ $+\mathrm{u}$

Keterangan :

$\mathrm{Y}=$ hasil produksi $(\mathrm{Kg} / / \mathrm{Mt})$

$\mathrm{X}_{1}=$ luas lahan $(\mathrm{Ha})$

$\mathrm{X}_{2}=$ jumlah benih $(\mathrm{Kg} / \mathrm{Mt})$

$\mathrm{X}_{3}=$ jumlah pupuk urea $(\mathrm{Kg} / \mathrm{Mt})$

$\mathrm{X}_{4}=$ jumlah pupuk NPK $(\mathrm{Kg} / \mathrm{Mt})$

$\mathrm{X}_{5}=$ jumlah herbisida (Liter/Mt)

$\mathrm{X}_{6}=$ jumlah insektisida (Liter/M)

$\mathrm{X}_{7}=$ curahan tenaga kerja luar keluarga(HOK/Mt)

$\mathrm{a}=$ Intersept (konstanta)

$b_{1} \ldots \ldots, b_{7}=$ parameter penduga dan merupakan elastisitas produksi dari faktor produksi. 
$\mathrm{u}=$ kesalahan (disturbance term)

Menurut Supranto (1995) untuk mengetahui besarnya proporsi (persentase) sumbangan variabel $X$ terhadap variabel $Y$ dicari nilai koefisien determinasi berganda $\left(R^{2}\right)$ sebagai berikut:

$\mathrm{R}^{2} \quad=\mathrm{ESS} / \mathrm{TSS}$

Keterangan :

ESS $=$ jumlah kuadrat regresi

TSS = total jumlah kuadrat yaitu jumlah kuadrat regresi

Adapun uji hipotesis yang digunakan adalah :

a. Uji F

Pengujian hipotesis pertama digunakan uji serentak (uji F). Uji F digunakan untuk menguji keberartian koefisien regresi (signifikasi) keseluruhan variabel bebas terhadap terikat.

Tabel 3. Analisis Varian

\begin{tabular}{|c|c|c|c|}
\hline Sumber variasi & $\begin{array}{c}\text { Jumlah kuadrat } \\
\text { (SS) }\end{array}$ & $\begin{array}{c}\text { Derajat } \\
\text { kebebasan (df) }\end{array}$ & $\begin{array}{l}\text { Rata-rata kuadrat } \\
\text { (MSS) }\end{array}$ \\
\hline $\begin{array}{c}\text { Dari regresi (ESS) } \\
\text { Kesalahan penggunaan (RSS) }\end{array}$ & $\begin{array}{c}\mathrm{R}^{2}\left(\sum Y_{1}^{2}\right) \\
\left(1-R^{2}\right)\left(\sum Y_{1}^{2}\right)\end{array}$ & $\begin{array}{l}k-1 \\
n-k\end{array}$ & $\begin{array}{l}\mathrm{MSR}=\mathrm{ESS} / \mathrm{df} \\
\mathrm{MSE}=\mathrm{RSS} / \mathrm{df}\end{array}$ \\
\hline TSS & $\mathbf{s} \mathbf{y}_{i}^{2}$ & $n-1$ & \\
\hline
\end{tabular}

Berdasarkan tabel tersebut, maka F-hitung dapat dicari dengan menggunakan rumus sebagai berikut:

$\mathrm{F}=\frac{\mathrm{ESS} /(\mathrm{k}-1)}{\operatorname{RSS} /(\mathrm{n}-\mathrm{k})}$

Keterangan :

$\mathrm{F} \quad=$ nilai $\mathrm{F}$-hitung

ESS $=$ Expalined Sum Square (rata-rata kuadrat regresi)

$\mathrm{RSS}=$ Residual Sum Square (rata-rata kuadrat sesidual)

$\mathrm{k} \quad=$ banyak variabel termasuk konstanta

$\mathrm{n} \quad=$ jumlah data

Hipotesis yang akan diajukan :

Ho : b1 = b2 =b3 = b4 =b5 = b7 =0

Semua variabel independen secara bersama-sama tidak berpengaruh terhadap produksi tanaman padi lahan tadah hujan.

$\mathrm{Hi}$ : paling tidak salah satu $\mathrm{bi} \neq 0$

( $i=1,2,3,4,5,6,7$ )

Paling tidak salah satu dari variabel independen berpengaruh terhadap produksi padi lahan tadah hujan. 
Kaidah pengambilan keputusan adalah sebagai berikut:

1. Apabila F-hitung $\leq \mathrm{F}$-tabel $5 \%$, maka terima Ho berarti semua variabel independen (luas lahan, benih, pupuk, pestisida dan tenaga kerja) secara bersama-sama tidak berpengaruh nyata terhadap produksi padi lahan tadah hujan.

2. Apabila F-hitung $>$ F-tabel $5 \%$ dan $1 \%$ maka tolak Ho berarti dari variabel independen (luas lahan, benih, pupuk, pestisida dan tenaga kerja) secara bersama-sama berpengaruh nyata terhadap produksi padi lahan tadah hujan.

b. Uji t

Pengujian hipotesis kedua dengan cara mencari terlebih dahulu koefisien dari $b_{i}$ yang paling besar, selanjutnya diuji signifikasinya dengan uji parsial (Uji t), menggunakan rumus sebagai berikut:

$$
\begin{aligned}
& \mathrm{t} \text {-hit }=\frac{\mathrm{b}_{\mathrm{i}}}{\mathrm{Seb} \mathrm{b}_{\mathrm{i}}} \\
& \mathrm{b}_{\mathrm{i}}=\frac{\sum X_{i} Y_{i}}{\sum X_{i}{ }^{2}} \\
& S e^{2}=\frac{\sum e_{i}^{2}}{n-k} \\
& S e b_{i}{ }^{2}=\frac{S e}{\sum X_{i}{ }^{2}} \\
& \Sigma e_{i}{ }^{e}=\left(1-R^{2}\right)\left(\Sigma Y_{i}^{2}\right)
\end{aligned}
$$

Uji hipotesis:

$\mathrm{Ho}: \mathrm{bi}=0,(\mathrm{i}=1,2,3,4,5,6,7)$

Masing-masing variabel bebas dalam model tidak berpengaruh terhadap produksi padi lahan tadah hujan.

$\mathrm{H} 1: \mathrm{bi} \neq 0,(\mathrm{i}=1,2,3,4,5,6,7)$

Masing-masing variabel bebas dalam model berpengaruh terhadap hasil produksi padi lahan tadah hujan.

Hipotesis yang digunakan adalah :

Kaidah dalam pengambilan keputusan adalah sebagai berikut :

1. Apabila t-hitung $\leq$ t-tabel $5 \%$ maka terima Ho berarti variabel independentidak berpengaruh terhadap produksi padi pada tingkat signifikasi $5 \%$.

2. Apabila t-hitung $>\mathrm{t}$-tabel $5 \%$ maka tolak Ho berarti variabel independen berpengaruh terhadap produksi padi pada tingkat signifikasi $5 \%$. 


\section{c. Uji Asumsi Klasik Regresi}

Setyadharma (2010) menjelaskan model regresi linier berganda (multiple regression) dapat disebut sebagai model yang baik jika model tersebut memenuhi beberapa asumsi yang kemudian disebut dengan asumsi klasik.

1. Uji Multikolinieritas

Multikolinieritas adalah keadaan dimana terjadi hubungan linear yang sempurna atau mendekati sempurna antar variabel independent dalam model regresi. Pengambilan keputusan jika output Coeffientsnilai VIF untuk masing-masing variable lebih besar dari 10 atau tidak. Bila nilai VIF lebih besar dari 10 maka diindikasikan model tersebut memiliki gejala Multikolinieritas (Setyadharma, 2010).

2. Uji Heteroskedastisitas

Heteroskedastisitas adalah keadaan dimana terjadi ketidak samaan varian dari residual untuk semua pengamatan pada model regresi. Pengambilan keputusan jika Unstandardizer Residual nilai signifikansi korelasi lebih dari 0,05, maka dapat disimpulkan bahwa pada model regresi tidak ditemukan adanya masalah heteroskedastisitas (Priyatno, 2010: 86).

\section{HASIL DAN PEMBAHASAN}

Berdasarkan karakteristik responden, dilihat dari umur petani sampel tergolong pada kelompopk usia produktif, yaitu 91,9\% dengan kisaran umur 20 - 60 tahun sehingga secara fisik cukup potensial untuk mendukung aktivitas kegiatan usahatani. Tingkat pendidikan petani responden secara umum masih rendah sebab sebagian besar petani responden tingkat pendidikannya hanya samapai tingkat SD yaitu sebesar 24 orang atau $64,87 \%$. Salah satu dari rendahnya pengetahuan petani responden mengenai usahatani padi dapat mengenai pengaruh penggunaan faktor-faktor produksi seperti masih menggunakan benih lokal dan penggunaan pupuk yang tidak sesuai anjuaran jumlah anggota keluarga responden yang tertinggi yaitu anatar 3-5 orang yang berjumlah 29 orang dengan persentase $78,38 \%$. Jumlah anggota keluarga petani responden yang relatif tinggi dapat menguntungkan bagi usahatani padi yang dilakukannya karena dengan semakin banyaknya jumlah anggota keluarga petani, maka dapat menekan biaya yang harus dikeluarkan untuk tenaga kerja luar keluarga. Petani responden rata-rata sudah memiliki pengalaman usahatani yang cukup lama. Hal ini dapat dilihat dari jumlah petani responden yang pengalaman usahataninya lebih dari 10 tahun yaitu sebesar 27 orang dengan persentase $72,97 \%$. Pengalaman usahatani responden yang cukup lama ini akan berpengaruh terhadap usahatani padi yang dilaksanakannya.

\section{Usahatani Padi Lahan Tadah Hujan di Desa Serindang}

Hasil penelitian menunjukan bahwa petani responden di daerah penelitian mengusahakan tanaman padi lokal varietas serendah unggul yang ditanam pada 2 musim tanam yaitu musim tanam satu (I) dan musim tanam dua (II). 
Tabel 4. Rata-rata Jumlah Penggunaan Faktor-faktor Produksi Musim Tanam Satu (I) dan Musim Tanam Dua (II) Pada Usahatani Padi Lahan Tadah Hujan di Desa Serindang Tahun 2011

\begin{tabular}{|c|l|c|c|}
\hline No & Faktor Produksi & $\begin{array}{c}\text { Rata-rata Jumlah } \\
\text { Penggunaan Musim Tanam } \\
\text { Satu (I) }\end{array}$ & $\begin{array}{c}\text { Rata-rata Jumlah } \\
\text { Penggunaan Musim } \\
\text { Tanam Dua (II) }\end{array}$ \\
\hline 1 & Luas lahan & $0,76 \mathrm{Ha}$ & $0,76 \mathrm{Ha}$ \\
2 & Benih & $45,54 \mathrm{Kg} / \mathrm{Mt}$ & $45,54 \mathrm{Kg} / \mathrm{Mt}$ \\
3 & Pupuk urea & $51,76 \mathrm{Kg} / \mathrm{Mt}$ & $46,62 \mathrm{Kg} / \mathrm{Mt}$ \\
4 & Pupuk NPK & $48,51 \mathrm{Kg} / \mathrm{Mt}$ & $43,51 \mathrm{Kg} / \mathrm{Mt}$ \\
5 & Herbisida & $2,77 \mathrm{liter} / \mathrm{Mt}$ & $2,36 \mathrm{Liter} / \mathrm{Mt}$ \\
6 & Insektisida & $1,84 \mathrm{liter} / \mathrm{Mt}$ & $1,58 \mathrm{Liter} / \mathrm{Mt}$ \\
7 & TKLK & $61,16 \mathrm{HOK} / \mathrm{Mt}$ & $59 \mathrm{HOK} / \mathrm{Mt}$ \\
\hline
\end{tabular}

Sumber: Analisis Data Primer, 2012

\section{Analisis Fungsi Produksi Usahatani Padi Lahan Tadah Hujan Di Desa Serindang}

\section{Musim Tanam Satu (I)}

Hasil analisis regresi fungsi produksi usahatani padi lahan tadah hujan musim tanam satu (I) menunjukan bahwa nilai koefisien regresi determinasi $\left(R^{2}\right)$ pada table Model Summary yaitu sebesar 0,991 atau $99,1 \%$. Artinya $99,1 \%$ dari faktor produksi yang diteliti berpengaruh terhadap naik turunnya produksi, sedangkan sisanya $0,9 \%$ dipengaruhi faktor lain yang tidak dimasukkan dalam analisis regresi faktor produksi. Tingkat pengaruh faktor-faktor produksi (variabel bebas) secara bersama-sama terhadap hasil produksi (variabel terikat) dilakukan uji-F. F-hit $=437,527>\mathrm{F}$ table $(0,05)=(2,35)$ dan $\mathrm{F}$ tabel $(0,01)=(3,33)$ (Sugiono, 2003: 298) dengan demikian terdapat cukup bukti untuk menerima hipotesis $\mathrm{Hi}$, yaitu terdapat salah satu atau lebih variabel faktor produksi yang berpengaruh sangat nyata terhadap tingkat produksi yang digunakan pada usahatani padi secara bersama-sama mempengaruhi produksi.

Table 5. Hasil Analisis Fungsi Produksi Usahatani Padi Musim Tanam Satu (I) Pada Lahan Tadah Hujan Di Desa Serindang Tahun 2011

\begin{tabular}{|l|c|c|c|c|}
\hline \multicolumn{1}{|c|}{ Variabel } & $\begin{array}{c}\text { Koefisien } \\
\text { regresi }\end{array}$ & $\begin{array}{c}\text { Standar } \\
\text { defiasi }\end{array}$ & t-hitung & $\begin{array}{c}\text { Probabilitas } \\
\text { sig }\end{array}$ \\
\hline Konstanta & 3,637 & 0,156 & 23,267 & 0,000 \\
\hline Luas lahan & 1,097 & 0,086 & 12,821 & ${ }^{\star} 0,000$ \\
\hline Benih & $-0,058$ & 0,097 & $-0,601$ & 0,553 \\
\hline Pupuk urea & $-0,017$ & 0,050 & 0,335 & 0,740 \\
\hline Pupuk NPK & $-0,015$ & 0,041 & $-0,358$ & 0,723 \\
\hline Herbisida & 0,012 & 0,035 & 0,337 & 0,738 \\
\hline Insektisida & $-0,027$ & 0,024 & $-1,126$ & 0,270 \\
\hline TKLR & $-0,007$ & 0,046 & $-0,145$ & 0,886 \\
\hline
\end{tabular}

Sumber Analisis Data Primer, 2012

Keterangan : * berpengaruh nyata

Berdasarkan tabel 5 menunjukan maka dapat dibuat persamaan regresi berganda yaitu :

$\log Y=3,637+1,097 \log X_{1}-0,058 \log X_{2}+0,017 \log X_{3}-0.015 \log X_{4}+0,012 \log X_{5}-$ $0,027 \log X_{6}-0,007 \log X_{7}$ 


\section{Musim tanam dua (II)}

Hasil analisis musim tanam II menunjukan bahwa nilai koefisien regresi determinasi $\left(R^{2}\right)$ pada table Model Summary yaitu sebesar 0,988 atau 98,8\%. Artinya 98,8\% dari faktor produksi yang diteliti berpengaruh terhadap naik turunnya produksi, sedangkan sisanya $1,2 \%$ dipengaruhi faktor lain yang tidak dimasukkan dalam analisis regresi faktor produksi. Tingkat pengaruh factor-faktor produksi (variabel bebas) secara bersama-sama terhadap hasil produksi (variabel terikat) dilakukan uji-F. F-hit $=351,631>\mathrm{F}$ table $(0,05)=(2,35)$ dan $\mathrm{F}$ tabel $(0,01)=(3,33)$ (Sugiono, 2003: 298) dengan demikian terdapat cukup bukti untuk menerima hipotesis $\mathrm{Hi}$, yaitu terdapat salah satu atau lebih variabel faktor produksi yang berpengaruh sangat nyata terhadap tingkat produksi yang digunakan pada usahatani padi secara bersama-sama mempengaruhi produksi.

Tabel 6. Hasil Analisis Fungsi Produksi Usahatani Padi Musim Tanam Dua (II) Pada Lahan Tadah Hujan di Desa Serindang Tahun 2011

\begin{tabular}{|l|c|c|c|c|}
\hline \multicolumn{1}{|c|}{ Variabel } & $\begin{array}{c}\text { Koefisien } \\
\text { regresi }\end{array}$ & $\begin{array}{c}\text { Standar } \\
\text { defiasi }\end{array}$ & t-hitung & $\begin{array}{c}\text { Probabilitas } \\
\text { sig }\end{array}$ \\
\hline Konstanta & 3,689 & 0,186 & 19,842 & 0,000 \\
\hline Luas lahan & 1,179 & 0,100 & 11,812 & ${ }^{*} 0,000$ \\
\hline Benih & $-0,084$ & 0,113 & $-0,739$ & 0,466 \\
\hline Pupuk urea & 0,015 & 0,049 & 0,306 & 0,762 \\
\hline Pupuk NPK & $-0,036$ & 0,053 & $-0,673$ & 0,506 \\
\hline Herbisida & 0,057 & 0,043 & 1,332 & 0,193 \\
\hline Insektisida & $-0,014$ & 0,027 & $-0,511$ & 0,613 \\
\hline TKLR & $-0,020$ & 0,059 & $-0,341$ & 0,735 \\
\hline
\end{tabular}

Sumber Analisis Data Primer, 2012

Keterangan : * berpengaruh nyata

Berdasarkan tabel 6 menunjukan maka dapat dibuat persamaan regresi berganda yaitu :

$\log Y=3,689+1,179 \log X_{1}-0,084 \log X_{2}+0,015 \log X_{3}-0.036 \log X_{4}+0,057 \log X_{5}-$ $0,014 \log X_{6}-0,020 \log X_{7}$

Hasil analisis musim tanam I dan musim tanam II menunjukan hanya ada satu variabel yaitu luas lahan yang berpengaruh nyata terhadap peningkatan produksi usahatani padi. Sedangkan variabel benih, pupuk urea, pupuk NPK, herbisida, insektisida, dan TKLK tidak berpengaruh nyata terhadap produksi.

\section{a. Faktor Produksi Luas Lahan}

Hasil analisis usahatani musim tanam I menunjukan koefisien regresi pada faktor produksi luas lahan adalah 1,097, hal ini berarti setiap penambahan luas lahan sebesar $1 \%$ maka akan meningkatkan produksi padi sebesar $1,097 \%$ sedangkan hasil analisis usahatani musim tanam II menunjukan koefisien regresi pada faktor produksi luas lahan adalah 1,179, hal ini berarti setiap penambahan luas lahan sebesar $1 \%$ maka akan meningkatkan produksi padi sebesar $1,179 \%$. Pada nilai probabilitas, variabel luas lahan musim tanam I dan musim tanam II menunjukan angka 0.000 yang berarti tingkat kepercayaan hampir $100 \%$ yang berarti faktor produksi luas lahan berpengaruh nyata terhadap jumlah produksi. Semakin luas lahan produktif yang dimiliki petani, maka produksi yang dihasilkan juga akan semakin tinggi. Selain itu, semakin subur suatu lahan maka produksi yang dihasilkan juga akan semakin tinggi. 


\section{b. Faktor Produksi Benih}

Hasil analisis usahatani musim tanam I menunjukan koefisien regresi faktor produksi pada benih adalah -0 , 058. Pada probabilitas variabel benih menunjukan angka 0.553 atau $55,3 \%$ yang berarti faktor produksi benih tidak berpengaruh nyata terhadap jumlah produksi. Sedangkan hasil analisis usahatani musim tanam II menunjukan koefisien regresi faktor produksi pada benih adalah $-0,084$. Pada probabilitas variabel benih menunjukan angka 0.466 atau $46,6 \%$ yang berarti faktor produksi benih tidak berpengaruh nyata terhadap jumlah produksi. Hal ini dikarenakan benih yang digunakan pada usahatani padi yaitu benih lokal yang tidak merespon pada penggunaan pupuk. Sehingga walaupun dilakukan pemberian pupuk sesuai anjuran tidak akan meningkatkan produksi.

\section{c. Faktor Produksi Pupuk Urea}

Hasil analisis usahatani musim tanam I menunjukan koefisien regresi faktor produksi pada pupuk urea adalah 0,017. Pada probabilitas variabel pupuk urea menunjukan angka 0, 740 atau $74 \%$ yang berarti faktor produksi pupuk urea tidak berpengaruh nyata terhadap jumlah produksi. Sedangkan hasil analisis usahatani musim tanam II menunjukan koefisien regresi faktor produksi pada pupuk urea adalah 0,015. Pada probabilitas variabel pupuk urea menunjukan angka 0, 762 atau 76,2 \% yang berarti faktor produksi pupuk urea tidak berpengaruh nyata terhadap jumlah produksi.

\section{d. Faktor Produksi Pupuk NPK}

Hasil analisis usahatani musim tanam I menunjukan koefisien regresi faktor produksi pada pupuk NPK adalah -0,015. Pada probabilitas variabel pupuk NPK menunjukan angka 0, 723 atau $72,3 \%$ yang berarti faktor produksi pupuk NPK tidak berpengaruh nyata terhadap jumlah produksi. Sedangkan hasil analisis usahatani musim tanam II menunjukan koefisien regresi faktor produksi pada pupuk NPK adalah -0,036. Pada probabilitas variabel pupuk NPK menunjukan angka 0, 506 atau 50,6\% yang berarti faktor produksi pupuk NPK tidak berpengaruh terhadap jumlah produksi.

\section{e. Faktor Produksi Herbisida}

Hasil analisis usahatani musim tanam I menunjukan koefisien regresi faktor produksi pada herbisida adalah 0,015 . Pada probabilitas variabel herbisida menunjukan angka 0,738 atau $73,8 \%$ yang berarti faktor produksi herbisida tidak berpengaruh nyata terhadap jumlah produksi. Sedangkan hasil analisis usahatani musim tanam II menunjukan koefisien regresi faktor produksi pada herbisida adalah 0,057. Pada probabilitas variabel herbisida menunjukan angka 0,193 atau $19,3 \%$ yang berarti faktor produksi herbisida tidak berpengaruh nyata terhadap jumlah produksi.

\section{f. Faktor Produksi Insektisida}

Hasil analisis usahatani musim tanam I menunjukan koefisien regresi faktor produksi pada insektisida adalah $-0,027$. Pada probabilitas variabel insektisida menunjukan angka 0,270 atau $27 \%$ yang berarti faktor produksi insektidida tidak berpengaruh nyata terhadap jumlah produksi. Sedangkan hasil analisis usahatani musim tanam II menunjukan koefisien regresi faktor produksi pada insektisida adalah -0,014. Pada probabilitas variabel insektisida menunjukan angka 0,613 atau $61,3 \%$ yang berarti faktor produksi insektidida tidak berpengaruh nyata terhadap jumlah produksi.

\section{g. Faktor Produksi Tenaga Kerja Luar Keluarga (TKLR)}

Hasil analisis usahatani musim tanam I menunjukan koefisien regresi faktor produksi pada TKLK adalah $-0,007$. Pada probabilitas variabel TKLK menunjukan angka 0, 886 atau $88,6 \%$ yang berarti faktor produksi TKLK tidak berpengaruh nyata terhadap jumlah produksi. Sedangkan hasil analisis usahatani musim tanam II menunjukan koefisien regresi faktor produksi pada TKLK adalah $-0,020$. Pada probabilitas variabel TKLK 
menunjukan angka 0,735 atau $73,5 \%$ yang berarti faktor produksi TKLK tidak berpengaruh nyata terhadap jumlah produksi.

\section{KESIMPULAN DAN SARAN}

\section{Kesimpulan}

Berdasarkan hasil penelitian dan pembahasan yang telah dilakukan, maka dapat diambil kesimpulan bahwa usahatani padi di Desa Serindang pada musim tanam satu (I) dan musim tanam dua (II) hanya penggunaan faktor produksi luas lahan yang berpengaruh nyata terhadap produksi, sedangkan faktor produksi benih, pupuk urea, pupuk NPK, herbisida, insektisida dan TKLK tidak berpengaruh nyata terhadap peningkatan produksi padi. Hal ini dipengaruhi oleh penggunaan benih lokal yang tidak merespon terhadap penggunaan pupuk, faktor alam yaitu curah hujan tidak menentu yang mengakibatkan pengairan tidak terkontrol yang berpengaruh pada pertumbuhan tanaman padi. Sehingga mengakibatkan penggunaan faktor produksi benih, pupuk urea, pupuk NPK, herbidida, insektidida dan TKLK tidak berdampak signifikan pada peningkatan produksi padi.

\section{Saran}

1. Sebaiknya petani di Desa Serindang menggunakan benih unggul yang respon terhadap penggunaan pupuk, supaya hasil produksi bisa meningkat produksi padi.

2. Ketersedian air untuk lahan sangat penting untuk diperhatikan yaitu dengan dengan membuat saluran irigasi supaya penggunaan faktor-faktor produksi usahatani padi lahan tadah hujan di desa Serindang bisa meningkatkan produksi padi.

\section{DAFTAR PUSTAKA}

Badan Litbang Pertanian. 2008. Sawah Tadah Hujan pun Sangat Menjanjikan.http://www.litbang.deptan.go.id. Di akses tanggal 4 Januari 2012 jam 11:39 WIB.

Badan Penyuluhan Pertanian. 2010. Programa Penyuluh Pertanian BPP Tebas Kabupaten Sambas. KecamatanTebas.

Badan Pusat Statistik. 2010. Kecamatan Tebas dalam Angka. Badan Pusat Statistik. Kalimantan Barat. Pontianak.

Nawawi, H. 1991. Metode Penelitian Bidang Sosial. Gadjah Mada University Press. Yogyakarta.

Nazir, M. 1988. Metode Penelitian. Ghalia Indonesia. Jakarta.

Priyatno, D. 2010. Paham Analisa Statistika Data dengan SPSS. Mediakom. Jogjakarta.

Setyadharma, A. 2010. Uji asumsi klasik dengan SPSS 16.0. http://blog.unnes.ac.id. Di akses tanggal 13 maret 2012 jam 15:32 WIB.

Soekartawi. 2003. Teori Ekonomi Produksi. PT. Raja Grafindo Persada. Jakarta.

Sugiyono. 2003. Statistik untuk Penelitian. CV ALFABETA. Bandung.

Suparmoko, M. 1991. Metode Penelitian Praktis (Ilmu Sosial Dasar dan Ekonomi).BPFE. Yogyakarta.

Supranto, J. 1995. Ekonometrika. LPFE-Ui. Jakarta. 